\title{
Controllable Synthesis of Fusiform-shaped Te@Au hybrids for Efficient Electrocatalytic Oxidation of Isopropanol
}

\author{
Huile Jin ${ }^{1,2}$, Liyun Chen ${ }^{1}$, Aili Liu ${ }^{1,2}$, Dewu Yin ${ }^{2}$, Guodong Yu ${ }^{2}$, Shun Wang ${ }^{2, *}$, \\ Weizhong Jiang ${ }^{1, *}$ \\ ${ }^{1}$ College of Materials Science and Engineering, Donghua University, Shanghai, P. R. of China 201620; \\ ${ }^{2}$ Nano-materials \& Chemistry Key Laboratory, Wenzhou University, Wenzhou, Zhejiang, China \\ 325035 \\ *E-mail: shunwang@wzu.edu.cn, jwzh@dhu.edu.cn
}

doi: $10.20964 / 2017.03 .43$

Received: 28 November 2016 / Accepted: 15 January 2017 / Published: 12 February 2017

\begin{abstract}
In this study, Te@Au hybrids with the shape of fusiform were successfully prepared through a simple two-phase interfacial reaction and were subsequently applied as the electrocatalysts for the oxidation of isopropanol. Comparing with poly-Au, the Te@Au hybrids showed excellent performance in the oxidation of isopropanol, such as higher limiting current density, better stability, etc. Characterization with electron scanning microscopy reveals that there are numerous edges and defects on the Te@Au surface. The presence of a large number of defects/edges on the catalyst surface, together with the intimate connection between $\mathrm{Te}$ and $\mathrm{Au}$, is suggested to be responsible for the observed high electrocatalytic performance. This study presents a new direction for developing low-cost, highly efficient electrocatalysts of direct alcohol fuel cell.
\end{abstract}

Keywords: Te@Au hybrids; Isopropanol; electrocatalytic oxidation; Direct alcohol fuel cell

\section{$\underline{\text { FULL TEXT }}$}

(C) 2017 The Authors. Published by ESG (www.electrochemsci.org). This article is an open access article distributed under the terms and conditions of the Creative Commons Attribution license (http://creativecommons.org/licenses/by/4.0/). 